\title{
Breast cancer characteristics in very young Egyptian women $\leq 35$ years
}

This article was published in the following Dove Press journal:

Breast Cancer:Targets and Therapy

5 April 2016

Number of times this article has been viewed

\section{Omar Farouk'}

Mohamed A Ebrahim²

Ahmad Senbel'

Ziad Emarah ${ }^{2}$

Waleed Abozeed ${ }^{3}$

Mohamed O Seisa ${ }^{4}$

Summer Mackisack ${ }^{4}$

Salah Abdel Jalil ${ }^{4}$

Safaa Abdelhady ${ }^{4}$

'Surgical Oncology Unit, ${ }^{2}$ Medical Oncology Unit, Oncology Center, Faculty of Medicine, ${ }^{3}$ Clinical

Oncology and Nuclear Medicine Department, ${ }^{4}$ Faculty of Medicine, Mansoura University, Mansoura, Egypt
Correspondence: Omar Farouk Surgical Oncology Unit, Oncology Center, Faculty of Medicine, Mansoura University, Gehan Street, 355II, Mansoura, Egypt Tel +20 I22 6902626

Email dr_omarfarouk@yahoo.com
Background: Breast cancer in very young patients represents a unique issue that needs more attention as the number of cases is increasing and it has special characteristics at presentation, diagnosis, and biologic behaviors which reflect on both treatment strategies and survival. The aim of the current study was to analyze and report the clinico-pathological characteristics and treatment procedures used for breast cancer in very young patients over the last decade in a single Egyptian cancer center.

Patients and methods: A retrospective study was conducted in the Oncology Center Mansoura University, where the data of all breast cancer patients, between September 2006 and August 2015, were reviewed. Among 4,628 patients who were diagnosed with breast cancer during this period, only 300 patients aged $\leq 35$ years had complete registry data. Clinicopathological characteristics, therapeutic procedures, and survival outcome were reported.

Results: Three hundred and seventy-nine patients $(8.19 \%)$ were aged $\leq 35$ years at the time of presentation. The age ranged between 21 and 35 years, and the mean age was 31 years $( \pm 3$ standard deviation). Positive family history of breast cancer was found in $12.3 \%$, and metastatic presentation was seen in $4.7 \%$. The rate of axillary lymph nodes involvement was $75.7 \%$. The estrogen receptor-negative disease was found in 51\%, and among 217 patients who did HER2 test, 82 patients $(37.8 \%)$ were HER2 positive, while triple-negative subtype was found in 57 patients (26.4\%). Ki 67 percentage ranged between $3 \%$ and $66 \%$ (median was $35 \%$ ). The median disease-free survival was 61 months (95\% confidence interval 44-78 months); the 3-year and 5 -year disease-free survival were $58 \%$ and $50 \%$, respectively. The 3 -year and 5-year overall survival were $88 \%$ and $68 \%$, respectively.

Conclusion: Very young Egyptian patients with breast cancer should be given focus and specially studied as the presentation has more aggressive biologic behavior at advanced stages, so the treatment strategies have to be tailored in a very precise manner.

Keywords: breast cancer, very young, survival, Egypt

\section{Introduction}

Breast cancer is the most common cancer in women. Its incidence increases with age; however, very young females represent a special group of patients having special requirements in management because breast cancer in young women is considered aggressive and associated with a poor prognosis., ${ }^{1,2}$ Moreover, very young women have higher incidence of advanced stages at diagnosis and poorer 5-year survival than older premenopausal patients. ${ }^{1-3}$ This may be attributed to some worse biologic features including higher incidence of grade 3 tumor, and estrogen receptor (ER)negative status. ${ }^{4,5}$ 
There are less publications describing breast cancer characteristics in very young Egyptian women $<35$ years, so the aim of the present study was to analyze the clinicopathological characteristics and describe the current different therapeutic strategies and survival outcome of those very young Egyptian women with breast cancer.

\section{Patients and methods}

This study has been approved by the Institutional Research Board of the Faculty of Medicine in Mansoura University with regards to the patients rights and medical ethics. All participating patients provided written informed consent to take part in this study. This is a retrospective study conducted in the Oncology Center-Mansoura University, where the data of all breast cancer patients between September 1, 2006 and August 31, 2015 were reviewed. Among 4,628 patients who were diagnosed with breast cancer during this period, 379 patients were aged $\leq 35$ years. Only 300 young patients had complete registry data, so they were included in the current study, and 79 patients were excluded as they were missing important registry data.

We gathered the clinico-pathological characteristics of those 300 patients who were aged $<35$ years at the time of diagnosis. Also, diagnostic and therapeutic procedures, follow-up visits, and survival were recorded.

Hormone receptors status was assessed by immunohistochemical tests for ER and progesterone receptor. The results were interpreted as positive when at least $1 \%$ of the invasive carcinoma cells displayed nuclear reactivity. HER2 testing was first performed by immunohistochemical test; score 3+ was interpreted as positive, and score 2+ was considered equivocal and was regarded as positive if confirmed by validated in situ hybridization technique.

\section{Statistics}

Data were analyzed on a personal computer running SPSS for windows (Statistical Package for Social Sciences) Release 17. For descriptive statistics of qualitative variables, the frequency distribution procedure was run with calculation of the number of cases and percentages. For descriptive statistics of quantitative variables, the mean, median, range, and standard deviation were used to describe central tendency and dispersion. Survival and progression-free survival analyses were performed using the Kaplan-Meier Product-Limit Estimator.

\section{Results}

The incidence of breast cancer in very young Egyptian women ( $\leq 35$ years) was $8.19 \%$ (379/4,628 patients). As regards the results of 300 young patients who had complete registry data, the age ranged between 21 and 35 years, and the mean age was 31 years ( \pm 3 standard deviation). The marital status was single in 43 patients (14.3\%), and 73 patients (24.3\%) had only one child, 70 patients $(23.3 \%)$ had two children, and 114 patients (38\%) had three children. Positive family history of breast cancer was found in 37 patients (12.3\%); among them, 13 patients (4.3\%) had family history affecting the mother, 15 patients $(5 \%)$ had family history affecting an aunt, and five patients (1.7\%) had family history affecting the mother and aunt; however, negative family history of breast cancer was found in 263 patients (87.7\%). Thirteen patients (4.3\%) were pregnant at the time of diagnosis. Bilateral presentation had occurred only in one patient $(0.33 \%)$, and metastatic presentation was shown in 14 patients (4.7\%). Patients' characteristics are summarized in Table 1.

The histopathologic types were invasive ductal carcinoma in 243 patients (81\%), invasive lobular carcinoma in 39 patients (13\%), and medullary carcinoma in ten patients $(3.3 \%)$, and other types were recorded in eight patients $(2.7 \%)$. Associated in situ components were recorded in 54 patients (18\%). Tumor grading showed that grades 1 , 2, and 3 were represented in nine (3\%), 199 (66.3\%), and $92(30.7 \%)$ of the tumors, respectively. Tumor size ranged between 0.6 and $12 \mathrm{~cm}$ (the median was $3 \mathrm{~cm}$ ), the number of resected lymph nodes ranged between eight and 32 (the median was 13), and the number of positive lymph nodes ranged between zero and 28 (the median was three). Tumor pathologic characteristics are summarized in Table 2.

A total of $176(58.7 \%)$ patients' tumors were hormone receptor positive, and among 217 patients who had the HER2 test, 82 patients (37.8\%) were HER2 positive and 135 patients $(62.2 \%)$ were HER2 negative. Ki 67 percentage ranged between $3 \%$ and $66 \%$ (median was $35 \%$ ). Analysis of breast cancer subtypes included 216 cases with complete data. Only seven patients (3.2\%) presented with luminal A-like

Table I Patients' characteristics

\begin{tabular}{llll}
\hline Personal data & Item & $\mathbf{N}=\mathbf{3 0 0}$ & $\%$ \\
\hline Marital status & Single & 43 & 14.3 \\
& One child & 73 & 24.3 \\
& Two children & 70 & 23.3 \\
& Three children & 114 & 38 \\
Family history & No & 263 & 87.7 \\
& Mother & 13 & 4.3 \\
& Aunt & 15 & 5 \\
& Sister & 4 & 1.3 \\
Pregnancy at presentation & Mother and aunt & 5 & 1.7 \\
& Yes & 13 & 4.3 \\
& No & 287 & 95.7 \\
\hline
\end{tabular}

Abbreviation: No, number. 
Table 2 Tumor pathologic characteristics

\begin{tabular}{|c|c|c|c|}
\hline Tumor characteristics & Item & $\mathrm{No}=\mathbf{3 0 0}$ & $\%$ \\
\hline \multirow[t]{3}{*}{ Side } & $\mathrm{Rt}$ & 158 & 52.7 \\
\hline & Lt & $|4|$ & 47 \\
\hline & Bilateral & I & 0.3 \\
\hline \multirow[t]{4}{*}{$\mathrm{T}$} & 1 & 46 & 15.3 \\
\hline & 2 & 175 & 58.3 \\
\hline & 3 & 40 & 13.3 \\
\hline & 4 & 39 & 13 \\
\hline \multirow[t]{4}{*}{ N } & 0 & 73 & 24.3 \\
\hline & I & 81 & 27 \\
\hline & 2 & 65 & 21.7 \\
\hline & 3 & 81 & 27 \\
\hline \multirow[t]{2}{*}{ M } & 0 & 286 & 95.3 \\
\hline & I & 14 & 4.7 \\
\hline \multirow[t]{4}{*}{ Pathology types } & IDC & 243 & 81 \\
\hline & ILC & 39 & 13 \\
\hline & Medullary & 10 & 3.3 \\
\hline & Other & 8 & 2.7 \\
\hline \multirow[t]{2}{*}{ Associated in situ components } & No & 246 & 82 \\
\hline & Yes & 54 & 18 \\
\hline \multirow[t]{4}{*}{ Grade } & I & 9 & 3 \\
\hline & 2 & 199 & 66.3 \\
\hline & 3 & 92 & 30.7 \\
\hline & Median & Mean (SD) & Range \\
\hline Tumor size & 3.0 & $3.9(2.1)$ & $0.6-12.0$ \\
\hline LN positive & 3 & $5(6)$ & $0-28$ \\
\hline LN resected & 13 & $14(5)$ & $8-32$ \\
\hline
\end{tabular}

Abbreviations: Rt, right; Lt, left; T, tumor; N, node; M, metastasis; IDC, invasive ductal carcinoma; ILC, invasive lobular carcinoma; SD, standard deviation; LN, lymph node; No, number.

breast cancer. The majority of patients presented with luminal B-like subtype (107 cases, 49.5\%). HER2 overexpression in non-luminal type was found in 45 cases (20.8\%). Interestingly, triple-negative subtype was found in 57 patients (26.4\%). Tumor biomarker characteristics are summarized in Table 3 .

As regards the treatment options (Table 4), all patients received chemotherapy. Neoadjuvant therapy was administrated in 132 patients (44\%), and pathologic complete response was achieved in 21 patients (15.9\%).

Surgery was performed in non-metastatic patients $(\mathrm{N}=286)$; modified radical mastectomy was done in 134 patients $(46.9 \%)$, conservative breast surgery was done in 65 patients $(22.7 \%)$, and conservative (sparing) mastectomies with immediate breast reconstruction using latissimus dorsi flaps were done in 87 (30.4\%) patients; among them, 70 patients (24.5\%) had nipple-sparing mastectomy, and 17 patients $(5.9 \%)$ had skin-sparing mastectomy.

Radiotherapy was administrated in 267 patients (89\%), and endocrine therapy was administrated in 176 patients (58.7\%); 126 patients (42\%) received Tamoxifen, and 50 patients $(16.7 \%)$ received Tamoxifen plus leutenizing
Table 3 Tumor biomarker characteristics

\begin{tabular}{llll}
\hline Biomarkers & Item & No & $\%$ \\
\hline ER & Negative & 153 & $5 \mathrm{I}$ \\
& Positive & 147 & 49 \\
PR & Negative & 145 & 48.3 \\
Hormone receptors & Positive & 155 & 51.7 \\
& Negative & 124 & 41.3 \\
HER2 (2I7 cases) & Positive & 176 & 58.7 \\
& Negative & 135 & 62.2 \\
Subtypes (2I6 cases) & Positive & 82 & 37.8 \\
& Luminal A-like & 7 & 3.2 \\
& Luminal B-like & 107 & 49.5 \\
& HER2 overexpression & 45 & 20.8 \\
& Triple-negative & 57 & 26.4 \\
Ki 67 (\%) & Median & Mean (SD) & Range \\
\hline
\end{tabular}

Abbreviations: ER, estrogen receptor; PR, progesterone receptor; SD, standard deviation; No, number.

Table 4 Treatment options

\begin{tabular}{|c|c|c|c|}
\hline Management & Item & No & $\%$ \\
\hline \multirow{5}{*}{$\begin{array}{l}\text { Surgery ( } 286 \text { non- } \\
\text { metastatic cases) }\end{array}$} & MRM & 134 & 46.9 \\
\hline & $\begin{array}{l}\text { Conservative mastectomies }+ \\
\text { immediate breast reconstruction }\end{array}$ & 87 & 30.4 \\
\hline & NSM + LD & 70 & 24.5 \\
\hline & SSM + LD & 17 & 5.9 \\
\hline & $\mathrm{BCS}$ & 65 & 22.7 \\
\hline \multirow[t]{3}{*}{ Chemotherapy } & Metastatic & 14 & 4.7 \\
\hline & Neoadjuvant & 132 & 44 \\
\hline & Adjuvant & 154 & 51.3 \\
\hline \multirow{4}{*}{$\begin{array}{l}\text { Complete PCR after } \\
\text { neoadjuvant therapy } \\
\text { (1 } 32 \text { cases) }\end{array}$} & No & $\mathrm{III}$ & 84.1 \\
\hline & & & \\
\hline & & & \\
\hline & Yes & 21 & 15.9 \\
\hline \multirow[t]{2}{*}{ Radiotherapy } & No & 33 & 11 \\
\hline & Yes & 267 & 89 \\
\hline \multirow[t]{3}{*}{ Endocrine therapy } & No & 124 & 41.3 \\
\hline & Tamoxifen & 126 & 42 \\
\hline & Tamoxifen + LHRH & 50 & 16.7 \\
\hline \multirow{2}{*}{$\begin{array}{l}\text { Trastuzumab ( } 82 \\
\text { positive cases) }\end{array}$} & No & 2 & 2.4 \\
\hline & For I year & 80 & 97.6 \\
\hline
\end{tabular}

Abbreviations: MRM, modified radical mastectomy; NSM, nipple-sparing mastectomy; LD, latissimus dorsi; SSM, skin-sparing mastectomy; BCS, breastconserving surgery; PCR, pathologic complete response; LHRH, leutenizing hormone-releasing hormone; No, number.

hormone-releasing hormone. Trastuzumab was administrated in 80 patients among those 82 patients with positive HER2.

The median disease-free survival (DFS) was 61 months (95\% confidence interval 44-78 months); the 3-year and 5 -year DFS was $58 \%$ and $50 \%$, respectively (Figure 1). The 3 -year and 5-year overall survival (OS) was $88 \%$ and $68 \%$, respectively (Figure 2). 


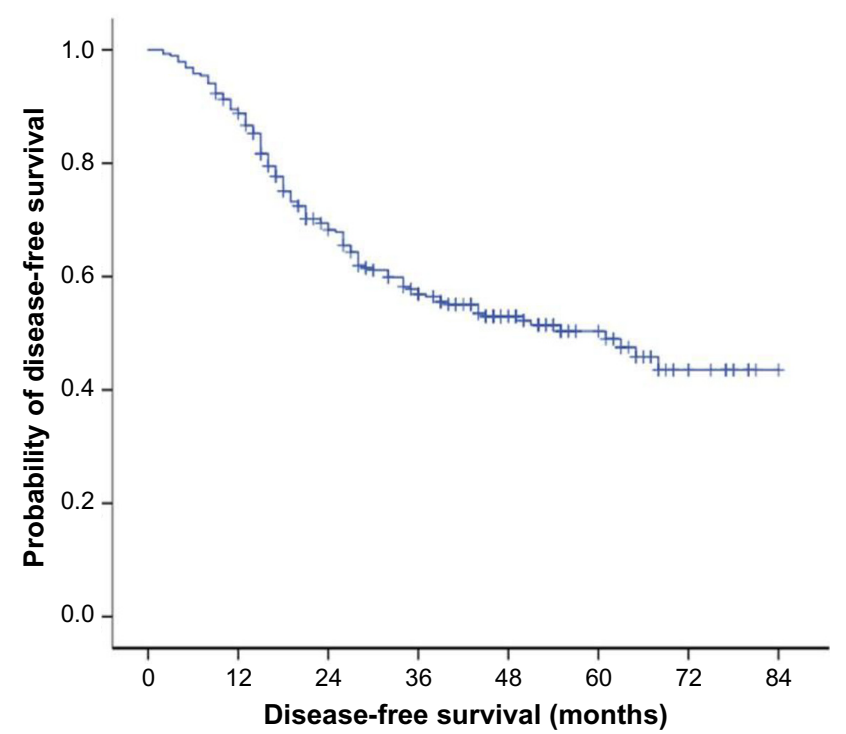

Figure I The median DFS was 6 I months (95\% confidence interval 44-78 months); the 3 -year and 5-year DFS were $58 \%$ and $50 \%$, respectively. Abbreviation: DFS, disease-free survival.

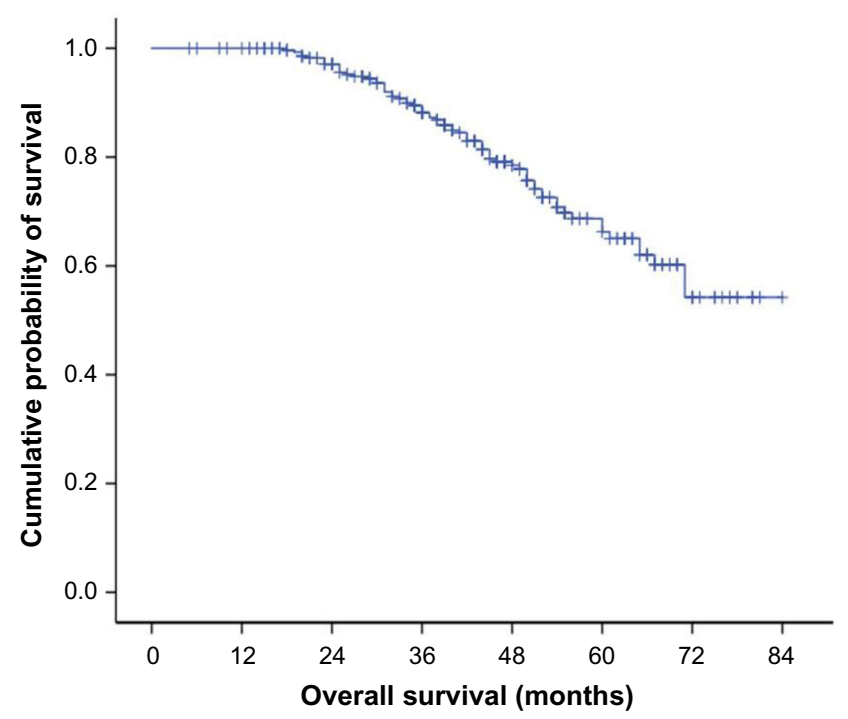

Figure 2 The 3 -year and 5-year OS were $88 \%$ and $68 \%$, respectively. Abbreviation: OS, overall survival.

\section{Discussion}

The definition of a young woman varies in the breast oncology field. Most authors are defining women under either age 35 or 40 years as "young" ${ }^{6}$ However, in the current study, we used the term very young referring to those women who were aged $\leq 35$ years while preserving the term young for those women under the age of 40 years.

Although breast cancer is the most common cancer in women, its incidence among young women widely varies in literature. Approximately $7 \%$ of women are diagnosed with breast cancer below the age of $40 .^{7}$ It may differ according to race. In Finland, during the year 2008, only $1 \%$ of the patients were younger than 35 years, ${ }^{8}$ while $2.7 \%$ of young Japanese patients were diagnosed with breast cancer $\left(<35\right.$ years). ${ }^{9}$ Among American women who were diagnosed with breast cancer between 2000 and 2005, 6.6\% of them were diagnosed before age 40 , and $2.4 \%$ diagnosed before age 35. In People's Republic of China, the proportion of young age-onset breast cancer (35 years old or younger) was very high, reaching $11.1 \%$ of patients. ${ }^{10}$

In the current study, we reported an incidence of $8.19 \%$ who were aged $<35$ years among 4,628 patients who were diagnosed with breast cancer over 10 years (2006-2015) in the Oncology Center-Mansoura University, Egypt. However, previous Egyptian retrospective study carried out on 1,009 female patients with operable non-metastatic primary breast cancer who were treated at the Radiotherapy Department of the National Cancer Institute of Cairo, Egypt, between 1999 and 2003, showed that $20.7 \%{ }^{11}$ were young Egyptian patients ( $<35$ years) Another Egyptian Study of 6,996 patients with breast cancer over 10 years (1999-2008) in Gharbiah, Egypt, showed that the overall incidence among patients aged $<40$ years was $17.2 \%{ }^{12}$

Breast cancer in younger women is mostly diagnosed at a later stage, and is of higher grade, has less ER positivity, and has a greater chance of recurrence. ${ }^{4,13-17}$

The ER negative disease in the current study was $51 \%$ which was higher than the figure recorded $(40 \%)$ in the Finnish study which was carried on 214 patients ( $\leq 35$ years) ${ }^{19}$ However, positive HER2 in our study was seen in $37.8 \%$ which was similar to the figure recorded (34\%) in the Finnish study. ${ }^{18}$

The involvement of axillary lymph nodes in young women when compared with older patients is high. ${ }^{19}$ A Nepali study with 944 breast cancer patients identified that axillary lymph nodes were positive in $73 \%$ of younger patients ( $<40$ years) and $59 \%$ of older patients $(P=0.002) .{ }^{20}$ In our study, the rate of axillary lymph nodes involvement was $75.7 \%$. These findings indicate the severity and aggressiveness of the disease in this age group.

Similar to other studies, the most frequent histological type of breast cancer in young women was infiltrating ductal carcinoma. ${ }^{20-22}$ In the current study, its incidence was $81 \%$; however, it was $95 \%$ in an analytical Tunisian retrospective survey among women with breast cancer younger than 35 years. ${ }^{23}$

In the present study, younger women were more likely to develop grade $2(66.3 \%)$ and grade $3(30.7 \%)$ tumors. This is similar to the study of Bouzid et al which found that grade 2 and 3 tumors were present in $41.1 \%$ and $37.1 \%$ of cases, respectively. ${ }^{23}$ 
As worldwide, young Egyptian females with breast cancer are generally treated similarly to their older counterparts; for example, the neoadjuvant chemotherapy is given to those who present with locally advanced breast cancer, and the surgical options are either mastectomy (with or without immediate breast reconstruction) or breast-conserving surgery followed by radiotherapy. As in older women, factors affecting surgical decisions include tumor size, location, ability to achieve a free safety margin with good cosmetic outcome, and patient preference. In the current study, the percentage of breastconserving surgery was $22.7 \%$ versus $77.3 \%$ for mastectomy. This may be attributed to that the relatively local advanced disease is present among those patients and most of the young females are worried about intramammary recurrence, so they prefer to do mastectomy.

Adjuvant chemotherapy is used more frequently in young women than in older women, ${ }^{9}$ probably because of longer life expectancy and better tolerability to aggressive treatments and documented survival advantages compared to women not treated with adjuvant therapy. ${ }^{24}$ In our study, all patients received chemotherapy.

But still, the younger patients received more mastectomies even with small tumors, more axillary surgery, and more chemotherapy. This may be due to the higher portion of additional ductal carcinoma in situ in the young cohort, a higher percentage of patients with history of breast cancer in the family, and perhaps even a higher need for maximal safety of therapy by the treating clinician. ${ }^{25}$

Breast cancer in young women is thought to have an aggressive biological behavior and is associated with a poor prognosis and less favorable survival. ${ }^{1,2}$ A Finnish study, which included 214 patients aged $\leq 35$ years with breast cancer during 1997-2007, revealed a DFS of $70 \%$ (the median disease free interval was 30 months, and range was 8-103 months), and the 5-year OS was $80 \% .{ }^{18}$ However, in the current study, the 5-year DFS was 50\% (the median diseasefree interval was 61 months, and range was 44-78 months), and the 5-year OS was $68 \%$. The reason for the poorer DFS and OS survival of young women in our study compared to the Finnish study seems to be different tumor characteristics and treatments.

\section{Conclusion}

Very young patients with breast cancer in Egypt constitute a unique group of patients as they have special tumor characteristics. This group has more advanced presentation, with much more aggressive biologic behavior, and has a significantly higher malignant axillary lymph node involvement.
So, therapy for each young patient with breast cancer has to be evaluated carefully and individually, and the treatment strategies have to be tailored in a very precise manner.

\section{Disclosure}

The authors report no conflicts of interest in this work.

\section{References}

1. Anders CK, Hsu DS, Broadwater G, et al. Young age at diagnosis correlates with worse prognosis and defines a subset of breast cancers with shared patterns of gene expression. J Clin Oncol. 2008;26(20):3324-3330.

2. Hartley MC, McKinley BP, Rogers EA, et al. Differential expression of prognostic factors and effect on survival in young $(<$ or $=40)$ breast cancer patients: a case-control study. Am Surg. 2006;72(12):1189-1194; discussion 1194-1195.

3. Holli K, Isola J. Effect of age on the survival of breast cancer patients. Eur J Cancer. 1997;33(3):425-428.

4. Collins LC, Marotti JD, Gelber S, et al. Pathologic features and molecular phenotype by patient age in a large cohort of young women with breast cancer. Breast Cancer Res Treat. 2012;131:1061-1066.

5. Colleoni M, Rotmensz N, Peruzzotti G, et al. Role of endocrine responsiveness and adjuvant therapy in very young women (below 35 years) with operable breast cancer and node negative disease. Ann Oncol. 2006;17:1497-1503.

6. Gabriel CA, Domchek SM. Breast cancer in young women. Breast Cancer Res. 2010;12:212.

7. Anders CK, Johnson R, Litton J, Phillips M, Bleyer A. Breast cancer before age 40 years. Semin Oncol. 2009;36:237-249.

8. Finnish Cancer Registry. Cancer in Finland 2008 and 2009. Cancer Society of Finland Publication No. 84, Helsinki 2011; 2011. Available from: http://www.cancer.fi/@Bin/70942478/SR_2008-2009_030112. pdf. Accessed January 26, 2016.

9. Kataoka A, Tokunaga E, Masuda N, Shien T, Kawabata K, Miyashita M. Clinicopathological features of young patients ( $<35$ years of age) with breast cancer in a Japanese Breast Cancer Society supported study. Breast Cancer. 2014;21:643-650.

10. Tang J, Wu CC, Xie ZM, Luo RZ, Yang MT. Comparison of clinical features and treatment outcome of breast cancers in young and elderly Chinese patients. Breast Care (Basel). 2011;6:435-440.

11. El Mongy M, El Hossieny H, Haggag F, Fathy R. Clinico-pathological study and treatment results of 1009 operable breast cancer cases: experience of NCI Cairo University, Egypt. Chin German J Clin Oncol. 2010;9(7);409-415

12. Hirko KA, Soliman AS, Hablas A, et al. Trends in breast cancer incidence rates by age and stage at diagnosis in Gharbiah, Egypt, over 10 years (1999-2008). J Cancer Epidemiol. 2013;2013:916394.

13. Gnerlich JL, Deshpande AD, Jeffe DB, Sweet A, White N, Margenthaler JA. Elevated breast cancer mortality in women younger than age 40 years compared with older women is attributed to poorer survival in early-stage disease. J Am Coll Surg. 2009;208(3):341-347.

14. Bleyer A, Barr R, Hayes-Lattin B, Thomas D, Ellis E, Anderson B. The distinctive biology of cancer in adolescents and young adults. Nat Rev Cancer. 2008;8(4):288-298.

15. Keegan TH, DeRouen MC, Press DJ, Kurian AW, Clarke CA. Occurrence of breast cancer subtypes in adolescent and young adult women. Breast Cancer Res. 2012;14(2):R55.

16. Partridge AH, Hughes ME, Ottesen RA, et al. The effect of age on delay in diagnosis and stage of breast cancer. Oncologist. 2012;17(6):775-782.

17. Partridge AH, Gelber S, Piccart-Gebhart MJ, et al. Effect of age on breast cancer outcomes in women with human epidermal growth factor receptor 2-positive breast cancer: results from a herceptin adjuvant trial. J Clin Oncol. 2013;31(21):2692-2698. 
18. Liukkonen S, Leidenius M, Saarto T, Sjöström-Mattson J. Breast cancer in very young women. Eur J Surg Oncol. 2011;37(12):1030-1037.

19. Foo CS, Su D, Chong CK, et al. Breast cancer in young Asian women: study on survival. ANZ J Surg. 2005;75(7):566-572.

20. Thapa B, Singh Y, Sayami P, Shrestha U, Sapkota R, Sayami G. Breast cancer in young women from a low risk population in Nepal. Asian Pac J Cancer Prev. 2013;14(9):5095-5099.

21. Khanfir A, Frikha M, Kallel F, et al. Le cancer du sein de la femme jeune dans le sud tunisien. [Breast cancer in young women in the south of Tunisia]. Cancer Radiotherapie. 2006;10:565-571. French.

22. Bakkali H, Marchal C, Lesur-Schwander A, Verhaeghe JL. Le cancer du sein chez la femme de 30 ans et moins. [Breast cancer in women thirty years old or less]. Cancer Radiotherapie 2003;7:153-159. French.
23. Bouzid N, Lahmar R, Tebra S, Bouaouina N. Cancer du sein chez la femme jeune de moins de 35 ans en Tunisie: etude retrospective 'a propos de 124 cas. [Breast cancer in woman younger than 35 years in Tunisia: retrospective study about 124 cases]. Gynecologie Obstetrique and Fertilite. 2013;41:356-360. French.

24. Shimizu C. Breast cancer in young women: its biological and clinical uniqueness and needs of comprehensive care. Breast Cancer. 2014;21:641-642.

25. Banz-Jansen C, Heinrichs A, Hedderich M, et al. Are there changes in characteristics and therapy of young patients with early-onset breast cancer in Germany over the last decade? Arch Gynecol Obstet. 2013;288:379-383.

\section{Publish your work in this journal}

Breast Cancer: Targets and Therapy is an international, peerreviewed open access journal focusing on breast cancer research, identification of therapeutic targets and the optimal use of preventative and integrated treatment interventions to achieve improved outcomes, enhanced survival and quality of life for the cancer patient.
View the full aims and scopes of this journal here. The manuscript management system is completely online and includes a very quick and fair peer-review system, which is all easy to use. Visit http:// www.dovepress.com/testimonials.php to read real quotes from published authors.

Submit your manuscript here: http://www.dovepress.com/breast-cancer---targets-and-therapy-journal 